\title{
Editorial
}

\section{Frontiers in Spatial and Spatiotemporal Crime Analytics-An Editorial}

\author{
Marco Helbich ${ }^{1, *}$ and Michael Leitner ${ }^{2}$ \\ 1 Department of Human Geography and Spatial Planning, Utrecht University, 3584 CS Utrecht, \\ The Netherlands \\ 2 Department of Geography and Anthropology, Louisiana State University, \\ E-104 Howe Russell Geoscience Complex, Baton Rouge, LA 70803, USA; mleitne@lsu.edu \\ * Correspondence: m.helbich@uu.nl; Tel.: +31-30-253-2017
}

Academic Editor: Wolfgang Kainz

Received: 1 March 2017; Accepted: 3 March 2017; Published: 6 March 2017

Environmental criminological theory is well-developed [1,2] but analytical techniques to explore and model crime incidents are lagging behind. Due to the emergence and accumulation of a wide range of environmental data [3], volunteered geographic information [4], unstructured textual information [5], and (big) statistical data [6], among others, it is of particular relevance to keep pace with these developments and make use of such spatial and temporal data. The integration of such data is highly relevant for space-time crime analytics, potentially providing new insight into local crime hotspots supporting law enforcements to combat crime.

While geographic information system-based methods [7] and spatial statistical approaches have nowadays gained momentum to map crime patterns [8], advanced data-driven computational methods (e.g., machine learning, Bayesian spatiotemporal models) are still in their infancy and are far from being mainstream (e.g., $[9,10])$. However, other disciplines provide evidence that these approaches are highly capable of solving classification problems, conducting inference, forecasting, and extracting patterns hidden in data that are otherwise overseen by basic methods [11,12]. Therefore, the amalgamation of criminology with computational methods seems to be a rational next step in the research agenda.

To address this, the prime aim of this Special Issue Frontiers in Spatial and Spatiotemporal Crime Analytics was to publish original research or review papers in order to stimulate further discussion on the development and application of the latest data-driven scientific advances to understand crime patterns and criminal behavior, their dynamics over time and across space, and the underlying key mechanisms. We anticipate that this methodological progress will yield more reliable risk assessments and more accurate predictions of crime as demanded by criminal justice agencies and needed for evidence-based criminal justice decision-making. The collection of paper provides a selection of actual approaches useful for, but not limited to, audiences that include researchers, postgraduates, and professionals. This Special Issue is a follow-up publication on a Special Issue [13] on crime mapping principles and we believe that this new collection of papers will contribute to the contemporary research agenda on crime modeling from a computational and data-driven perspective.

As indicated by the response to the call for manuscripts, it appears that the intention of this Special Issue received wide approval. By the end of December 2016 (submission deadline), a total of ten manuscripts were submitted. Each manuscript was evaluated through a single-blind review process by at least two international experts. For the review process, the standard MDPI review guidelines were used. Besides the innovative aspect of the research, the scientific quality of the research weighted heavily on the decision of whether or not a manuscript was accepted or rejected. In cases where major revisions were requested by reviewers and to guarantee high scientific quality, a second round of review of the revised manuscript by at least one of the original reviewers or an alternative reviewer was conducted. If reviews called for minor revisions, then a second round of reviews was not done. Instead, 
the guest editors made the decision whether or not the revised manuscript was fit for publication. In March 2017, seven papers out of ten were accepted and are now included in this Special Issue.

The present Special Issue is compiled of the following papers: Using Swedish residential burglaries data, Boldt and Borg [14] proposed a novel temporal analysis method to approximate offense times for residential burglaries and cross-compared it with existing aoristic methods. The paper by Glasner and Leitner [15] was dedicated to repeat victimization through street robberies between 2009 and 2013 in Vienna, Austria, utilizing geovisualization coupled with spatial and temporal analyses. Promoting a rich set of spatial econometrics models, Mburu and Bakillah [16] assessed the burglary risk for Greater London, UK. Complementing their global regression, Du and Law [17] explored the spatially heterogeneous associations between vegetation and transportation networks on crime in Kitchener-Waterloo, Canada, by means of geographically weighted regressions. Sypion-Dutkowska and Leitner [18] investigated how land use influences the spatial distribution of different crime types in Szczecin, Poland, using standard geospatial analyses. Finally, two papers documented the strengths of the Bayesian modeling paradigm for spatial and spatiotemporal criminology. Marco et al. [19] employed Bayesian spatial modeling to test neighborhood characteristics on drug-related police interventions in Valencia, Spain. Using Integrated Nested Laplace Approximation, Luan et al. [20] modeled call-for-service data in the Waterloo region (Canada) whereas space-time interactions are explicitly taken into account at a small-area level.

Taken together, what these papers in this Special Issue have demonstrated is that spatial data analyses are already an established approach. While for point patterns space-time analyses are accepted, explicit space-time regressions are on the rise but are still in their infancy. As crime patterns are inherently dynamic and are affected by space-time varying risk and protective factors, we believe that these models have huge potential to increase our understanding of crime across space and over time. Somehow unexpected, even though this Special Issue only shows a limited view of the field, it became evident that computational methods such as agent-based simulation, data mining, or machine learning are still not wide-spread for crime analytics. In this respect, we still see the urgent need that crime research should adopt and consider such computational techniques successfully applied in other disciplines. Work in this direction seems to be a great promise for future research.

Acknowledgments: The editors express their gratefulness and gratitude to all reviewers for their support and their critical and constructive comments for each manuscript. This has added significantly to the quality of the entire volume. Finally, we thank Jie Wang and Yuanyuan Yang for editorial assistance throughout the preparation of this special issue.

Conflicts of Interest: The authors declare no conflict of interest.

\section{References}

1. Cohen, L.; Felson, M. Social change and crime rate trends: A routine activity approach. Am. Sociol. Rev. 1979, 44, 588-608. [CrossRef]

2. Brantingham, P.; Brantingham, P. Environmental Criminology; Sage: Beverly Hills, CA, USA, 1981.

3. Ceccato, V.; Uittenbogaard, A.; Bamzar, R. Security in Stockholm's underground stations: The importance of environmental attributes and context. Secur. J. 2013, 26, 33-59. [CrossRef]

4. Roth, R.; Ross, K.; Finch, B.; Luo, W.; MacEachren, A. Spatiotemporal crime analysis in US law enforcement agencies: Current practices and unmet needs. Govern. Inf. Quart. 2013, 30, 226-240. [CrossRef]

5. Helbich, M.; Hagenauer, J.; Leitner, M.; Edwards, R. Exploration of unstructured narrative crime reports-An unsupervised neural network and point pattern analysis approach. Cartogr. Geogr. Inf. Sci. 2013, 40, 326-336. [CrossRef]

6. Wang, T.; Cynthia, R.; Daniel, W.; Rich, S. Finding patterns with a rotten core: Data mining for crime series with cores. Big Data 2015, 3, 3-21. [CrossRef] [PubMed]

7. Chainey, S.; Ratcliffe, J. GIS and Crime Mapping; Wiley: Hoboken, NJ, USA, 2013.

8. Helbich, M.; Jokar Arsanjani, J. Spatial eigenvector filtering for spatiotemporal crime mapping and spatial crime analysis. Cartogr. Geogr. Inf. Sci. 2015, 42, 134-148. [CrossRef]

9. Berk, R. Algorithmic criminology. Secur. Inf. 2013, 2, 1-14. [CrossRef] 
10. Law, J.; Quick, M.; Chan, P. Analyzing hotspots of crime using a Bayesian spatiotemporal modeling approach: A case study of violent crime in the Greater Toronto Area. Geogr. Anal. 2015, 47, 1-19. [CrossRef]

11. Jordan, M.; Mitchell, T. Machine learning: Trends, perspectives, and prospects. Science 2015, 349, $255-260$. [CrossRef] [PubMed]

12. Hvistendahl, M. Crime forecasters. Science 2016, 353, 1484-1487. [CrossRef] [PubMed]

13. Leitner, M.; Helbich, M. Innovative crime modeling and mapping. Cartogr. Geogr. Inf. Sci. 2015, 42, 95-96. [CrossRef]

14. Boldt, M.; Borg, A. Evaluating temporal analysis methods using residential burglary data. ISPRS Int. J. Geo-Inf. 2016, 5, 148. [CrossRef]

15. Glasner, P.; Leitner, M. Evaluating the impact the weekday has on near repeat victimization: A spatio-temporal analysis of street robberies in the city of Vienna, Austria. ISPRS Int. J. Geo-Inf. 2017, 6, 3. [CrossRef]

16. Mburu, L.W.; Bakillah, M. Modeling spatial interactions between areas to assess the burglary risk. ISPRS Int. J. Geo-Inf. 2016, 5, 47. [CrossRef]

17. Du, Y.; Law, J. How do vegetation density and transportation network density affect crime across an urban central-peripheral gradient? A case study in Kitchener-Waterloo, Ontario. ISPRS Int. J. Geo-Inf. 2016, 5, 118. [CrossRef]

18. Sypion-Dutkowska, N.; Leitner, M. Land use influencing the spatial distribution of urban crime. A case study of Szczecin, Poland. ISPRS Int. J. Geo-Inf. 2017. accepted.

19. Marco, M.; Gracia, E.; López-Quílez, A. Linking neighborhood characteristics and drug-related police interventions: A Bayesian spatial analysis. ISPRS Int. J. Geo-Inf. 2017, 6, 65. [CrossRef]

20. Luan, H.; Quick, M.; Law, J. Analyzing local spatio-temporal patterns of police calls-for-service using Bayesian integrated nested Laplace approximation. ISPRS Int. J. Geo-Inf. 2016, 5, 162. [CrossRef]

(c) 2017 by the authors. Licensee MDPI, Basel, Switzerland. This article is an open access article distributed under the terms and conditions of the Creative Commons Attribution (CC BY) license (http://creativecommons.org/licenses/by/4.0/). 